\title{
Research on Human-Error Factors of Civil Aircraft Pilots Based On Grey Relational Analysis
}

\author{
Yundong Guo, Youchao Sun and Si Chen \\ College of Civil Aviation, Nanjing University of Aeronautics and Astronautics, Nanjing, China
}

\begin{abstract}
In consideration of the situation that civil aviation accidents involve many human-error factors and show the features of typical grey systems, an index system of civil aviation accident human-error factors is built using human factor analysis and classification system model. With the data of accidents happened worldwide between 2008 and 2011, the correlation between human-error factors can be analyzed quantitatively using the method of grey relational analysis. Research results show that the order of main factors affecting pilot human-error factors is preconditions for unsafe acts, unsafe supervision, organization and unsafe acts. The factor related most closely with second-level indexes and pilot human-error factors is the physical/mental limitations of pilots, followed by supervisory violations. The relevancy between the first-level indexes and the corresponding second-level indexes and the relevancy between second-level indexes can also be analyzed quantitatively.
\end{abstract}

\section{Introduction}

With the rapid technological development, the number of civil aviation accidents caused by the faults of the electromechanical equipment has declined sharply. To the contrary, aviation accidents caused by inappropriate pilot operation is increasing year by year. Human-error factors have accounted for $60-80 \%$ of the whole accident causes, becoming one of the main causes of civil aviation accidents[1]. By now, the research on human-error factors mostly concentrates on qualitative analysis, such as cause \& effect analysis, event tree analysis, simulated investigation analysis, fishbone diagram analysis[2-5], and little improvement in the research on quantitative analysis has been realized. Quantitative research on cockpit human-error factors needs a great number of samples for mathematical statistics analysis, with high requirements for data integrity and data accuracy, and has not shown the relationship between human error and safety factors clearly. To reduce the aviation accident rate in China, it is of great importance to use the big data of aviation accidents to analyze the occurrence rules of human-error factors for higher pilot efficiency.

Based on the method of grey relational analysis, this paper researches the human-error factors of pilots in civil aircraft cockpits. There are many human-error factors that affect the task execution, the interactive environment and the interactive process are very complex and the relationship between human-error factors and other factors is still in an unclear grey system. Using grey relational analysis for the human-error factor research can remedy the limitations of traditional statistics analysis and provide theoretical basis for prohibiting and reducing human errors and mitigating flight risks.

\section{Method}

\section{1 grey relational analysis}

Grey correlation means uncertain correlation between objects, factors or between factors and main acts. The main idea is to judge how closely those objects are related based on geometry similarity between referential data sequences and comparative data sequences, which shows the relevance between curves. Finding out the main factor that affects the target values by calculating the relational degree is an easy and practical system analysis method, which can make up the shortages of traditional mathematical statistics method, such as demand of large samples, large amount of calculation and inconsistence between the results of quantitative analysis and qualitative analysis. The calculation process of grey relational analysis is as follows:

1)Determine the referential sequence, denoted as:

$$
X_{0}(k), \quad k=1,2, \cdots, m .
$$

2)Determine the comparative sequence, denoted as:

$$
X_{i}(k), \quad i=1,2, \cdots, n \text {. }
$$

3)Calculate the correlation coefficient between the referential sequence and the comparative sequence, denoted as: 


$$
\xi_{i}(k)=\frac{\min _{i} \min _{k}\left|X_{0}(k)-X_{i}(k)\right|+\rho \max _{i} \max _{k}\left|X_{0}(k)-X_{i}(k)\right|}{\left|X_{0}(k)-X_{i}(k)\right|+\rho \max _{i} \max _{k}\left|X_{0}(k)-X_{i}(k)\right|}
$$

$\rho \in(0,1)$ means the identification coefficient, and normally we take the value of 0.5 .

4)Calculate the relational degree, denoted as:

$$
\gamma_{i}=\frac{1}{n} \sum_{k=1}^{n} \xi_{i}(k)
$$

$\gamma_{i}$ means the relational degree between the sequence $X_{i}$ and the sequence $X_{0}$, and the higher value means the closer relationship.

5)Rank the relevancies according to their values, and find out the factors that affect the main act.

\subsection{Construction of human error index system}

Contingency exists in the occurrence of civil aviation accidents, and both dominant factors and recessive factors can result in human error, so it is hard to quantify the relationship between human-error factors. Based on the Human Factors Analysis and Classification System (HFACS)[6], we can classify the factors that affect the piloterror incidents as 4 first-level indexes (organizational influences, unsafe supervision, preconditions for unsafe acts and unsafe acts) and 18 second-level indexes. According to the cognitive process of aircraft operation, we can build the human error index system (see Fig 1) by analyzing the degree to which these second-level factors interact with each other.

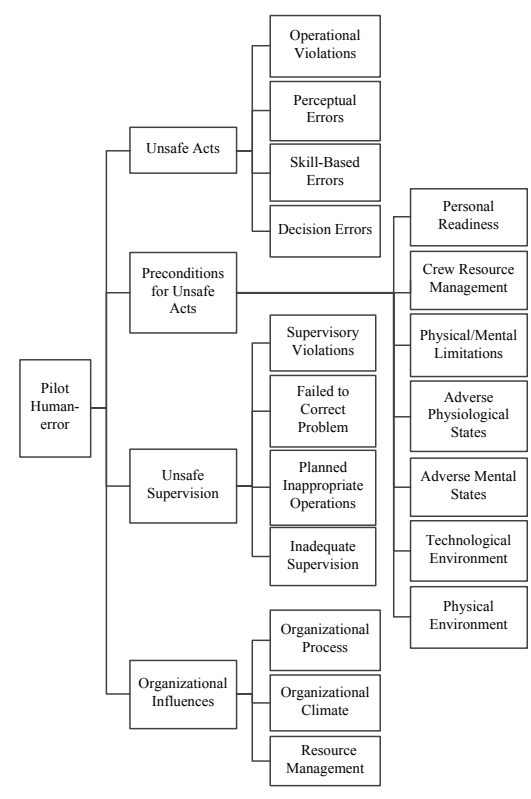

Figure 1. human error index system

\section{A Case study}

Use the materials of 88 civil aviation accidents happened worldwide in the recent four years: 23 accidents in 2008, 46 accidents in 2009, 17 accidents in 2010, and 2 accidents in
2011[7]. Based on HFACS model, analyze the human factors in those 88 accidents and find out that there are 347 human-error events, then summarize the analysis results for every year (see Table 1).

Table 1. Analysis Results of Human-error Events in Civil Aircraft

\begin{tabular}{|c|c|c|c|c|}
\hline Human Error Index & 2008 & 2009 & 2010 & 2011 \\
\hline $\begin{array}{l}\text { Organizational Influences } \\
\qquad \mathrm{X}_{1} \\
\end{array}$ & 12 & 25 & 8 & 4 \\
\hline $\begin{array}{l}\text { Resource Management } \\
\qquad \mathrm{X}_{11}\end{array}$ & 5 & 13 & 4 & 2 \\
\hline $\begin{array}{l}\text { Organizational Climate } \\
\qquad \mathrm{X}_{12}\end{array}$ & 2 & 2 & 0 & 0 \\
\hline $\begin{array}{l}\text { Organizational Process } \\
\qquad \mathrm{X}_{13}\end{array}$ & 5 & 10 & 4 & 2 \\
\hline Unsafe Supervision $\mathrm{X}_{2}$ & 23 & 36 & 16 & 5 \\
\hline $\begin{array}{l}\text { Inadequate Supervision } \\
\qquad \mathrm{X}_{21}\end{array}$ & 7 & 12 & 5 & 2 \\
\hline $\begin{array}{c}\text { Planned Inappropriate } \\
\text { Operations } \mathrm{X}_{22}\end{array}$ & 5 & 5 & 1 & 0 \\
\hline $\begin{array}{l}\text { Failed to Correct Problem } \\
\qquad \mathrm{X}_{23} \\
\end{array}$ & 6 & 8 & 5 & 1 \\
\hline $\begin{array}{c}\text { Supervisory Violations } \\
\qquad \mathrm{X}_{24}\end{array}$ & 5 & 11 & 5 & 2 \\
\hline $\begin{array}{l}\text { Preconditions for Unsafe } \\
\text { Acts } \mathrm{X}_{3} \\
\end{array}$ & 28 & 52 & 20 & 5 \\
\hline Physical Environment $\mathrm{X}_{31}$ & 3 & 11 & 6 & 0 \\
\hline $\begin{array}{c}\text { Technological } \\
\text { Environment } X_{32}\end{array}$ & 15 & 20 & 4 & 1 \\
\hline $\begin{array}{l}\text { Adverse Mental States } \\
\qquad \mathrm{X}_{33} \\
\end{array}$ & 1 & 5 & 2 & 1 \\
\hline $\begin{array}{c}\text { Adverse Physiological } \\
\text { States } \mathrm{X}_{34} \\
\end{array}$ & 1 & 3 & 1 & 1 \\
\hline $\begin{array}{l}\text { Physical/Mental } \\
\text { Limitations } X_{35} \\
\end{array}$ & 1 & 2 & 1 & 0 \\
\hline $\begin{array}{c}\text { Crew Resource } \\
\text { Management } \mathrm{X}_{36}\end{array}$ & 7 & 8 & 6 & 1 \\
\hline Personal Readiness $X_{37}$ & 0 & 3 & 0 & 1 \\
\hline Unsafe Acts $\mathrm{X}_{4}$ & 21 & 52 & 37 & 4 \\
\hline Decision Errors $X_{41}$ & 6 & 11 & 9 & 1 \\
\hline Skill-Based Errors $\mathrm{X}_{42}$ & 6 & 16 & 9 & 1 \\
\hline Perceptual Errors $X_{43}$ & 5 & 10 & 9 & 1 \\
\hline $\begin{array}{l}\text { Operational Violations } \\
\qquad \mathrm{X}_{44}\end{array}$ & 4 & 15 & 10 & 1 \\
\hline $\begin{array}{c}\text { Number of Human-error } \\
\text { Events } \mathrm{X}_{0}\end{array}$ & 84 & 165 & 80 & 18 \\
\hline
\end{tabular}
Accident at Home and Abroad From 2008 to 2011 


\subsection{Grey relational analysis of human errors and first-level indexes}

Set the amount of human error events (X0) in civil aviation accidents as the referential sequence, and set organizational influences (X1), unsafe supervision factors (X2), precondition for unsafe acts (X3) and unsafe acts (X4) as comparative sequences. Use the initial value method to nondimensionalize these sequences, and the results are as follows :

$$
\begin{aligned}
& X_{0}^{\prime}=X_{0} / X_{0}(2)=(0.5091,1.0000,0.4848,0.1139) \\
& X_{1}^{\prime}=X_{1} / X_{1}(2)=(0.4800,1.0000,0.3200,0.1600) \\
& X_{2}^{\prime}=X_{2} / X_{2}(2)=(0.6389,1.0000,0.4444,0.1389) \\
& X_{3}^{\prime}=X_{3} / X_{3}(2)=(0.5385,1.0000,0.3846,0.0962) \\
& X_{4}^{\prime}=X_{4} / X_{4}(2)=(0.4038,1.0000,0.7115,0.0769)
\end{aligned}
$$

Use the data in Table 1 and the relational degree formula to calculate the absolute difference $\Delta_{i}(k)$, the first-order minimum difference $\min _{k} \Delta_{i}(k)$, the first-order maximum difference $\max _{k} \Delta_{i}(k), \quad$ the second-order
minimum $\min _{i} \min _{k} \Delta_{i}(k), \quad$ and the second-order
$\operatorname{maximum} \max _{i} \max _{k} \Delta_{i}(k)$, and $\Delta_{i}(k)=\left|X_{0}(k)-X_{i}(k)\right|$
$\Delta_{i}(k)=\left|X_{0}(k)-X_{i}(k)\right|, X_{0}(k)=X_{0}^{\prime}, X_{i}(k)=X_{i}^{\prime}(k), i=1,2,3,4 \mathrm{~T}$ he results are shown in Table 2.

Table 2. Calculation Results of the Absolute Difference and the First-order Minimum/Maximum Difference

\begin{tabular}{|c|c|c|c|c|c|c|}
\hline$k$ & 1 & 2 & 3 & 4 & $\min _{k} \Delta_{i}(k)$ & $\max _{k} \Delta_{i}(k)$ \\
\hline$\Delta_{i}$ & $\begin{array}{c}0.0 \\
291\end{array}$ & $\begin{array}{c}0.00 \\
00\end{array}$ & $\begin{array}{c}0.16 \\
48\end{array}$ & $\begin{array}{c}0.04 \\
61\end{array}$ & 0.0000 & 0.1648 \\
\hline$\Delta_{2}$ & $\begin{array}{c}0.1 \\
298\end{array}$ & $\begin{array}{c}0.00 \\
00\end{array}$ & $\begin{array}{c}0.04 \\
04\end{array}$ & $\begin{array}{c}0.02 \\
50\end{array}$ & 0.0000 & 0.1298 \\
\hline$\Delta_{3}$ & $\begin{array}{c}0.0 \\
294\end{array}$ & $\begin{array}{c}0.00 \\
00\end{array}$ & $\begin{array}{c}0.10 \\
02\end{array}$ & $\begin{array}{c}0.01 \\
77\end{array}$ & 0.0000 & 0.1002 \\
\hline$\Delta_{4}$ & $\begin{array}{c}0.1 \\
053\end{array}$ & $\begin{array}{c}0.00 \\
00\end{array}$ & $\begin{array}{c}0.22 \\
67\end{array}$ & $\begin{array}{c}0.03 \\
70\end{array}$ & 0.0000 & 0.2267 \\
\hline
\end{tabular}

$\min _{i} \min _{k}\left|X_{0}(k)-X_{i}(k)\right|=0$

$\max _{i} \max _{k}\left|X_{0}(k)-X_{i}(k)\right|=0.2267$

The correlation coefficients and the results of gray relational grade calculation are as follows:

$$
\begin{aligned}
& \xi_{1}=(0.7957,1.0000,0.4075,0.7109) \\
& \xi_{2}=(0.4662,1.0000,0.7372,0.8193) \\
& \xi_{3}=(0.7940,1.0000,0.5308,0.8649)
\end{aligned}
$$

$\xi_{4}=(0.5184,1.0000,0.3333,0.7539)$

$\gamma_{1}=0.7285, \gamma_{2}=0.7556, \gamma_{3}=0.7974, \gamma_{4}=0.6514$

Apparently, the precondition for unsafe acts is the main factor that affects human error in civil aviation accidents, rather than unsafe supervision or unsafe organization. Notably, inadequate organizational management typically involves operational processes such as inadequate or nonexistent procedures, directives, standards, and requirements, or in the case of commuter/on-demand operations, inadequate surveillance of operations.

\subsection{Grey relational analysis of first-level indexes and second-level indexes}

Set 'organizational influences' $\mathrm{X} 1$ as the referential sequence, and set 3 second-level indexes of the first-level index $\mathrm{X} 1$ as the comparative sequence. Use the same method as above and we can get the relational degrees, respectively, between 3 second-level indexes (inappropriate resource management, bad organizational environments, mistakes in operational process) and the organizational influences:

$$
\begin{aligned}
& \gamma_{11}=0.9156, \gamma_{12}=0.6001, \\
& \gamma_{13}=0.8900, \text { and the ranking is } \gamma_{11}>\gamma_{13}>\gamma_{12} .
\end{aligned}
$$

The data shows that inappropriate resource management is the factor that has the most important effects on organizational influences. The reason why bad organizational environment has less impact may be that the accident reports are relatively simple. Some involved departments only include immediate causes and do not explore the root causes reflected by accidents. Organizational culture plays a key role in any flight accident.

The relational degrees between second-level indexes (inadequate supervision, planned inappropriate operations, failure to correct known problems and supervisory violations) and the first-level index 'unsafe supervision' are $\gamma_{21}=0.8750, \gamma_{22}=0.5810, \gamma_{23}=0.6710, \gamma_{24}=0.8120$.

and the ranking is $\gamma_{21}>\gamma_{24}>\gamma_{23}>\gamma_{22}$.

The data confirm the influences of unsafe supervision related with operational process and show that failure of known type may have something to do with involved operational type. For example, accidents of civil aviation are usually associated with the way procedures or instructions are delivered, but such accidents have closer relationship with the lack of organizational supervision. Actually, these databases can provide directions for solving the question how unsafe supervision threaten aviation safety.

Relational degrees between second-level indexes (physical environments, technology environments, adverse mental states, adverse physiological states, physical/mental limitations, aircrew resource management, and personal readiness) and the first-level index 'preconditions for unsafe acts' are ${ }^{\gamma_{31}}=0.5633$, 
$\gamma_{32}=0.6099, \gamma_{33}=0.6633, \gamma_{34}=0.5919, \gamma_{35}=0.6957$,

$\gamma_{36}=0.5716, \gamma_{37}=0.4312$. The ranking is $\gamma_{35}>\gamma_{33}>$

$\gamma_{32}>\gamma_{34}>\gamma_{36}>\gamma_{31}>\gamma_{37}$

The calculation results show that pilot mental/physical limitations result in most human errors in civil aviation accidents, and the main reason is that mental/physical limitations disable pilots to carry out flight control tasks successfully when failure or emergencies happen.

Relational degrees between second-level indexes (decision errors, skill-based errors, perceptual errors, violations) and the first-level index 'unsafe acts' are $\gamma_{41}=0.8187, \gamma_{42}=0.8650, \gamma_{43}=0.7411, \gamma_{44}=0.8614$.

The ranking is $\gamma_{42}>\gamma_{44}>\gamma_{41}>\gamma_{43}$.

When considering pilot personal conditions, the factor 'skill-based errors' has the highest relational degree with unsafe acts, such as unintentionally touching control device that is irrelevant to the current task or operating the process in wrong order. The followed is violations which include not conducting instructions from air traffic control department, unauthorized approaches and so on. Decision errors and perceptual errors are also important factors that can lead to accidents, for example, making risky decisions when time is limited.

\subsection{Grey relational analysis of human errors and second-level indexes}

Set X0 as the referential sequence, and set all the secondlevel indexes as comparative sequences. Use the initial value method to calculate relational degrees and we can get the ranking:

$$
\begin{aligned}
& \gamma\left(X_{0}, X_{35}\right)=0.8293>\gamma\left(X_{0}, X_{24}\right)=0.7684>\gamma\left(X_{0}, X_{43}\right) \\
& =0.7664>\gamma\left(X_{0}, X_{13}\right)=0.7631>\gamma\left(X_{0}, X_{21}\right) \\
& =0.7230>\gamma\left(X_{0}, X_{41}\right)=0.7181>\gamma\left(X_{0}, X_{42}\right) \\
& =0.6901>\gamma\left(X_{0}, X_{23}\right)=0.6610>\gamma\left(X_{0}, X_{11}\right) \\
& =0.6459>\gamma\left(X_{0}, X_{31}\right)=0.6213>\gamma\left(X_{0}, X_{36}\right) \\
& =0.6032>\gamma\left(X_{0}, X_{33}\right)=0.5988>\gamma\left(X_{0}, X_{32}\right) \\
& =0.5655>\gamma\left(X_{0}, X_{34}\right)=0.5389>\gamma\left(X_{0}, X_{22}\right) \\
& =0.4955>\gamma\left(X_{0}, X_{12}\right)=0.4717>\gamma\left(X_{0}, X_{44}\right) \\
& =0.4501>\gamma\left(X_{0}, X_{37}\right)=0.4268
\end{aligned}
$$

All the second-level factors are at the same level and what can be seen from the data are the influences that different types of factors exert on human errors. The most influential one is 'mental/physical limitations', one of the factors subjected to 'preconditions for unsafe acts', and the followed is 'supervisory violations' belonging to the factor 'unsafe supervision'.

\subsection{Grey relational analysis of second-level indexes}

Complex interactions exist among factors of the same level, and we can analyze the correlations between different factors by setting one factor as the referential sequence and setting other factors of the same level as comparative sequences. Set 'decision errors' as the referential sequence and set 'skill-based errors', 'perceptual errors', and 'violations' as comparative sequences, and the relational degrees are

$$
\begin{aligned}
& \gamma\left(X_{41}, X_{43}\right)=0.8050>\gamma\left(X_{41}, X_{42}\right)=0.6265>\gamma\left(X_{41}, X_{44}\right) . \\
& =0.4831
\end{aligned}
$$

The results indicate that perceptual errors have the most influences on decision errors, followed by skill-based errors and violations. Therefore, we can take control of the main factors to achieve the auxiliary control of cognitive errors on the impact of unsafe behavior, according to the degree of influence of cognition and skill on decision making.

\section{Conclusions}

Based on civil aviation accidents happened between 2008 and 2011, grey relational analysis can work out the main human error factor and the relational degrees between factors, offering the quantitative relationship between different human-error factors. The result of the analytic hierarchy process shows that, the major factor of human error is 'preconditions for unsafe acts', followed by unsafe supervision. According to the importance of factors, we can take targeted prevention or control measures to reduce human errors. Based on HFACS, grey relational analysis of human errors in civil aviation accidents can also be applied to accidents in nuclear plants, automobiles and collieries. Relational analysis can provide the order of importance of all the factors that contribute to the accident and will provide theoretical foundation of prevention measures.

\section{Acknowledgement}

This work was supported by National Natural Science Foundation of China (U1333119); Postgraduate Research \& Practice Innovation Program of Jiangsu Province (KYCX17-0273).

\section{References}

1. Dayong D, Jinhai Y, Baofeng L, et al. Acta Aeronaut. Astronaut Sin., 37(1):310-316 (2016)

2. Pengcheng L, Licao D, Li Z, et al. China Safety Science Journal, 20(4):75-82 (2010)

3. Kolny Olesiak J, Weller H. Acs Appl. Mat. Interfaces, 5(23):12221-12237 (2013)

4. Woodcock K, Drury C G, Smiley A, et al. Appl. Ergon., 36(1):1-12 (2005)

5. Ciocoiu C N, Ilie G. Knowledge Management Research \& Practice, 2(1):1-20 (2010)

6. Shappell S, Detwiler C, Holcomb K, et al. Human Factors, 49(2):227 (2007)

7. MinQin W, Bozhi G. Civil aircraft and incident statistics analysis manual (China Aviation Industry Press, 2015) 